\title{
EVALUASI FORMATIF DESAIN INSTRUKSIONAL DIKLAT JARAK JAUH PENELITIAN TINDAKAN KELAS
}

\author{
Asip Suryadi \\ Balai Diklat Keagamaan Jakarta, Indonesia \\ asipsuryadi@kemenag.go.id,asip_sayurradi@yahoo.co.id
}

\begin{abstract}
Classroom Action Research Online Training is one of the Online Training (Diklat Jarak Jauh) organized by Jakarta Religion Training Office (BDK Jakarta). The training has some weaknesses including low graduation rate and academic learning outcomes. It needs evaluation to formulate some revision in its instructional system. One of the important components should be evaluated is instructional design. This study explains formative evaluation results of the instructional design. The study was conducted to answer three questions, 1) Is the teaching material in accordance with the participants' wishes? 2). Is teaching material presented using the right strategy so that it is easy to learn? 3). Has the tutor service met the expectations of participants? The results of the study are expected to formulate recommendations for revision. Formative evaluations are conducted within the framework of Dick and Carey's instructional development model focuses on field trials level. The data was collected through surveys using ELL, activity logs, tutor records and recordings of participant's conversations on social media. Survey results are processed using descriptive statistics and qualitative data processed using content analysis. The research concluded that teaching materials and teaching strategies are low scored. Based on the conclusion, it is recommended to change the structure curriculum to ensure that the teaching materials are more detailed, implement more diverse learning strategies and apply Web 3.0 as a base to determine media in accordance with the learning style of the digital community.
\end{abstract}

Keywords: DJJ Online; instructional design, formative Evaluation.

\begin{abstract}
Abstrak
Diklat Jarak Jauh (DJJ) Online Penelitian Tindakan Kelas yang diselenggarakan BDK Jakarta memiliki beberapa kelemahan diantaranya tingkat kelulusan baru mencapai rata-rata $63.4 \%$ dan skor rata-rata hasil belajar dari keseluruhan kegiatan baru mencapai 68.5\%. Untuk meningkatkannya perlu dilakukan evaluasi dan revisi. Salah satu evalusi dan revisi dapat dilakukan pada komponen desain instrukssional. Penelitian ini menjelaskan hasil evlauasi formatif terhadap desain instruksional diklat tersebut. Penelitian dilakukan untuk menjawab tiga pertanyaan yaitu 1) Apakah materi ajar sudah sesuai dengan keinginan peserta? 2). Apakah materi ajar disajikan menggunakan strategi yang tepat sehingga mudah dipelajari? 3). Apakah pelayanan tutor sudah memenuhi harapan peserta? Hasil penelitian diharapkan dapat memrumuskan rekomendasi untuk revisi. Evaluasi formatif dilakukan dalam kerangka pengembangan instruksional Dick and Carey focus pada langkah uji lapangan (field trial). Data dikumpulkan melalui survey menggunakan instrument ELLS dan analisis konten terhadap data kualitatif bernetuk log kegiatan, catatan tutor dan rekaman perbincangan peserta di media sosial. Data hasil survey diolah menggunakan statistic deskriptif dan data kualitatif diolah menggunakan teknik induktif. Penelitian menyimpulkan bahwa materi ajar dan strategi pembeajran belum baik sedangkan mutu layanan tuotor sudah baik. Berdasarkan simpulan tersebut direkomendasikan untuk mengubah struktur kurikulum sehingga materi ajar pada beberapa bagian lebih rinci, menerapkan strategi pebelajaran yang lebih beragam dan menerapkan media berbasis teknologi 3.0 agar bahan ajar sesuai dengan karakter belajar masyarakat digital.
\end{abstract}

Kata Kunci: DJJ Online; desain instruksional; evaluasi formatif. 


\section{PENDAHULUAN}

Balai Diklat Keagamaan (BDK) Jakarta telah menyelenggarakan Diklat Jarak Jauh (DJJ) Online sejak tahun 2012-2013. Model Diklat tersebut disajikan untuk meningkatkan kesempatan kepada pegawai untuk memperoleh layanan Diklat dengan cara memanfaatkan teknologi informasi dan komunikasi yang semakin mudah dan murah.

Model Diklat tersebut telah berhasil menyelenggarakn Diklat yang efisien dan efektif. Dari segi efisiensi, DJJ dapat melipatgandakan output dengan efisiensi anggaran mencapai rata-rata 500\%. Dari segi efektifitas, hasil diklat lebih baik karena materi diklat berupa keterampilan teknis. Pada DJJ disajikan pelatihan sampai tingkat aplikasi, dan produk yang divalidasi tutor.

Namun demikian masih ditemukan beberapa kelamahan yang harus segera diatasi. Hasil evaluasi terhadap proses dan hasil pembelajaran pada keseluruhan DJJ yang disajikna ditemukan beberapa kekurangan. Beberapa temuan utama diantaranya tingkat kelulusan (graduation rate) baru mencapai ratarata dari $67 \%$, dan hasil belajar (retention rate) yang diukur dari skor hasil tes online kesempatan pertama (sebelum remedial) baru mencapai sor rata-rata $71 \%$ padahal skor batas lulus (passing grade) Diklat di Kementerian Agama adalah 76 (BDK-Jakarta, 2012).

Salah satu DJJ yang mengalami rendahnya jumlah kelulusan dan hasil belajar adalah DJJ Penelitian Tindakan Kelas. Pada DJJ ini tingkat kelulusan baru mencapai $63.4 \%$ dan skor ratarata hasil belajar dari keseluruhan kegiatan baru mencapai $68.5 \%$.
Kondisi tersebut menjadi masalah bagi BDK Jakarta sebagai lembaga pemerintah yang harus mengusung efisiensi sumber daya dan efektifitas proses. Oleh karena itu perlu dilakukan penelitian-penelitian yang komprehensif untuk menemukan solusi-solusi efektif agar masalah tersebut terselesaikan.

Penelitian mengenai proses dan hasil pembelajaran online sudah dilakukan di berbagai tempat. Beberapa penelitian menjelaskan kelebihan dan kelemahan online learning alam berbgai bentuk.

Arkorful dan Abaido mengidentifikasi delapan kelemahan utama online learning terkait dengan kelemahan tekis dan kelemahan psikologis peserta. Kelemahan teknis terkait dengan seperti keterbatasan fasilitas internet. Sedangkan kelemahan psikologis terkait dengan motivasi, kemandirian, kesepian dan dan kemungkinan mengalami kepanikan dalam mengikuti ujian online (Arkorful \& Abaidoo, 2015).

Selain itu ditemukan kelemahan substansial yaitu rendahnya tingkat penguasaan materi ajar (retention rate) dan rendahnya tingkat kelulusan (completion rate). Studi yang dilakukan Wilging dan Johnson menyatakan bahwa tingkat penyelesaian cenderung lebih rendah untuk kelas online daripada kelas tatap muka (Wilging \& Johnson, 2004).

Bawa mengutip hasil penelitian oleh Smith mencatat bahwa secara total, $40 \%$ hingga $80 \%$ siswa online keluar dari kelas online (Bawa, 2016). Park dan Choi mengutip penelitian Meister yang melaporkan bahwa 70\% pelajar dewasa yang mendaftar dalam program online perusahaan tidak 
menyelesaikannya dan Rostaminezed menyimpulkan bahwa dari laporan internasional, rata-rata angka ketidaklulusan dalam program pembelajaran online adalah sekitar 40\% (Park \& Choi, 2009).

Selanjutnya, Bawa menekankan bahwa kelas online terus menampilkan masalah retensi serius. Studi oleh Herbert menemukan bahwa kursus online memiliki tingkat retensi gagal $10 \%$ hingga $20 \%$ lebih tinggi daripada lingkungan kelas tradisional dan (Bawa, 2016). Penelitian oleh National Student Clearinghouse Research Center yang diterbitkan tahun 2014 menyatakan bahwa program online di universitas negeri memiliki tingkat retensi $68,2 \%$ dan swasta 72,9\% (Sorensen \& Donovan, 2017).

Sebagian besar penelitian menemukan bahwa faktor internal peserta didik sangat dominan kontribusinya terhadap rendahnya retensi dan kelulusan. Ulasan studi oleh Rostaminezhad et al. (2013), Sorensen dan Donovan (2018), dan Choi et al. (2015) mengungkapkan bahwa faktor motivasi, manajemen waktu, dukungan keluraga, dukungan organisasi, dan beban kerja adalah faktor-faktor yang dimaksud. Namun, Park dan Choi (2015) juga menemukan bahwa tidak hanya faktor internal tetapi juga faktor instruksional seperti desain pembelajaran merupakan faktor penting yang menentukan motivasi peserta didik.

Hasil studi tersebut memberikan landasan pada pengembangan pembelajaran online bahwa faktor internal dan faktor-faktor instruksional keduanya harus dipertimbangkan untuk membangun lingkungan pembelajaran online yang ramah- pengguna. Oleh karena itu Park dan Choi (2009) menekankan bahwa perancang instruksional harus secara sistematis menganalisis faktor-faktor eksternal di sekitar peserta dan menggunakan hasil analisis sebagai landasan untuk melakukan perbaikan berkesinambungan pada sistem instruksional. Dengan menimbang faktor tersebut diharapkan program instruksional lebih partisipatif, menarik dan membuat peserta didik tetap mengikuti program. Lebih tegas lagi Bawa menyarankan agar memikirkan aspek strategi dan media pembelajaran dalam pengembangan sistem instruksional tersebut.

Berdasarkan kajian di atas rendahnya tingkat kelulusan dan retensi dapat dilakukan dengan cara melakukan revisi pada aspek instruksional, media dan layanan. Revisi dilakuakn secara sistematis, terpadu dan berkesinambungan.

Untuk kebutuhan tersebut dilakukan evaluasi formatif terhadap desain instruksional DJJ Penelitian Tindakan Kelas. Evaluasi dilakukan menggunakan kerangka pengembangan instruksional pola Dick and Carey.

Untuk melakukan penelitian tersebut dirumuskan pertanyaan penelitian sebagai berikut: 1) Apakah materi ajar sudah sesuai dengan keinginan peserta? 2). Apakah materi ajar disajikan dengan strategi yangbtept sehingga mudah dipelajari? 3). Apakah pelayanan tutor sudah memenuhi harapan peserta?

Penelitian bertujuan untuk mengumpulkan data mengenai mutu materi ajar, strategi, media, penyajian dalam LM dan hasil belajarnya. Data yang dikumpulkan akan digunakan 
sebagai landasan untuk melakukan revisi. Hasil penelitian ini diharapkan dapat meningkatkan mutu proses dan hasil DJJ yang berujung terhadap peningkatan hasil belajar dan kelulusan khususnya pada DJJ Penelitian Tindakan Kelas, dan umumnya bagi seluruh jenis DJJ di BDK Jakarta.

\section{METODE}

Penelitian menggunakan metode evaluasi formatif dalam kerangka konsep pengembangan instruksional System Approach Model of Education Research and Development rancangan Dick dan Carey (Gall et al., 2015: 570571). Pada pola Dick dan Carey evaluasi formatif dilakukan melalui tiga langkah yaitu clinical evaluation (one-to-one), dan field trial. Karena langkah pertama dan kedua sudah dilakukan pada awal pengembangan, penelitian ini hanya akan dilakukan langkah ketiga yaitu field trial.

Pada penelitia ini dikumpulkan data mengenai mutu sistem pembelajaran online, data log kegiatan yang terekam dalam LMS, catatan tutor dan perbincangan peserta di media social. Untuk mengumpulkan data mengenai mutu system dilakukan teknik survey menggunakan angket $e$ Learning System Success (ELSS) DeLone-McLeans yang sudah dimodifikasi Wang (Wang et al., 2007: 1792-1808) dengan skala 5. Instrumen tersebut terdiri dari enam dimensi yaitu System Quality/Mutu Sistem (SQ), Information Quality/Mutu Materi Ajar, (IQ), Service Quality/Mutu Layanan (SeQ), Use/Dampak (U), User Satisfaction/Kepuasan Pengguna (US), Net Benefit/Manfaat (NB). Setiap dimensi dijabarkan kedalam item angket dengan jumlah sebagai berikut.

Tabel 1 Dimensi Pelatihan

\begin{tabular}{lc}
\hline \multicolumn{1}{c}{ DIMENSI } & JUMLAH ITEM \\
\hline Mutu Sistem & 7 \\
\hline Mutu Materi Ajar & 6 \\
\hline Mutu Layanan & 5 \\
\hline Dampak & 3 \\
\hline $\begin{array}{l}\text { Kepuasan } \\
\text { Pengguna }\end{array}$ & 3 \\
\hline Manfaat & \\
\hline Jumlah & 10 \\
\hline
\end{tabular}

Data kuantitatif diolah menggunakan statistik deskriptif, sedangkan data kualitatif diolah menggunakan teknik analisis konten. Analisis dilakukan melalui focus group discussion (FGD) melibatkan pengembang instruksional, pengembang materi, pengembang media dan tutor.

Penelitian di lakukan di Balai Diklat Keagamaan Jakarta bulan Juli sampai Desember 2018. Sumber data utama adalah log kegiatan dalam LMS DJJ Online penelitian Tindakan Kelas.

\section{HASIL DAN PEMBAHASAN}

Evaluasi formatif dimulai dengan survey persepsi peserta megenai mutu program menggunakan ELLS, kemudian dilakukan analisis data log LMS DJJ perbicangan dalam media sosial dan FGD. Melalui langkah tersebut diperleh data sebagai berikut.

\section{Data Penelitian}

\section{a. Hasil Survey ELLS}

Data hasil survei online mengenai e-learning system success telah 
ditabulasi. Data telah diklasisikasi kedalam enam dimensi ELLS dan dianalisis menggunakan statistic deskriptif yaitu rata-rata, skor tertinggi, skor terendah dan standar deviasi. Ringkasan data dapat dilihat dalam tabel berikut.

Tabel 2 Ringksan Data Hasil Survey

\begin{tabular}{lllll}
\hline & X & MAX & MIN & SD \\
\hline SQ & 4.25 & 4.39 & 3.89 & 0.12 \\
\hline IQ & 3.29 & 4.24 & 3.23 & 0.17 \\
\hline SE & 4.38 & 4.41 & 4.28 & 0.09 \\
\hline U & 3.45 & 4.43 & 3.21 & 0.05 \\
\hline US & 3.67 & 4.34 & 3.36 & 0.23 \\
\hline NB & 4.35 & 4.55 & 4.18 & 0.13 \\
\hline
\end{tabular}

Tabel 2 menun jukkan bahwa skor rata-rata rata-rata dari semua dimensi adalah 3,90 dengan standar deviasi rataa-rata 0,19 . Skor rata-rata tertinggi pada dimensi manfaat dan skor ratarata terendah padamutu materi ajar.

Pada enam dimensi tersebut terdapat tiga dimensi yang skornya di bwah rata-rata keseluruhan yaitu mutu materi ajar, dampak dan kepuasan pengguna. Data tersebut menunjukkan bahwa pada dimensi tersebut perlu dilakukan perbaikan.

\section{b. Data Log dan Catatan Lapangan}

Telah dilakukan analisis konten terhadap data log kegiatan yang terekam dalam LMS dan catatan tutor. Berdasarkan analisis tersebut diperoleh data mengenai komponenkomponen instruksional yang memerlukan evaluasi. Komponenkomponen tersebut meiputi kompetensi dasar, struktur kurikulum substansi materi, strategi pembelajaran, sumber dan media pembelajaran.
Pertama mngenai Kompetensi Dasar (KD). Pada desain instruksional dicanangkan tiga kompetensi dasar (KD) yaitu Memahami konsep dan prosedur PTK, Memahami komponen dan sistematika PTK dan Menyusun proposal PTK. Dengan komposisi seperti itu tutor mencatat bahwa KD kurang rinci. Dampaknya kegiatan belajar yang disajikan untuk menguasai setiap KD terlalu besar sehingga mengakibatkan satuan Kegiatan Belajar (KB) sarat dengan kegiatan. Hal itu menyebabkan kebosanan para peserta untuk menyelesaikan sebuah tema pembelajaran terlalu lama dan materi kurang rinci.

Selain itu banyak peserta yang cenderung memahami PTK sebagai penelitian positivistik sehingga rancangan PTK seperti rancangan eksperimen.

Kedua mengenai substansi materi. Ditemukan tiga hal penting yang harus dibahasa. a), peserta kesulitan memahami perbedaan antara PTK dengan penelitian lain. Hal ini disebabkan karena belum memahami posisi PTK dalam paradigma penelitian. b) Tugas hasil pra-PTK banyak yang kurang bermutu karena dilakukan seadanya. Akibatnya peserta kesulitan menyusun proposal akibat tidak lengkapnya data awal. Hal itu diprediksi merupakan idikasi dari kurang mendalamnya pembelajaran pasa sesi tersebut. c), Banyak peserta mengalami masalah dalam tata tulis ilmiah mulai dari pengutipan, penomoran halaman, sampai daftar pustaka. Selain itu masih ditemukan pengetikan yang masih sangat manual, padahal teknik penulisan ilmiah dapat dilakukan 
lebih mudah menggunakan fungsifungsi dalam aplikasi olah kata seperti Microsoft Word. d), Peserta melakukan banyak kekeliruan dalam menentkan dan menyusun instrumen penrlitian khususnya pada instrument penelitian kualitatif. Diprediksi karena peserta cenderung hanya menggunakan pola pikir kuantitatif dalam menyusunnya.

Ketiga mengenai struktur kurilulum. Berdasarkan catatan tutor diperoleh beberapa data penting yang berdampak terhadap tuntutan terhadap reviai struktur kurikulum. Pertama terkait KD yang terlalu gemuk. Yaitu pada Konsep dan Prosedur PTK. Kedua pada kegiatan seminar online proposal PTK. Ketiga pada metodologi pembelajaran yang menyatukan penyusunan bagian metodologi dengan instrument.

Keempat mengenai strategi pembelajaran. Materi dalam DJJ PTK termasuk materi yang paling sulit apabila dibandingkan dengan materi pada DJJ lainnya. Beberapa indikator dari sulitnya menguasai materi yang dimaksud adalah rendahnya kecepatan belajar dan rendahnya skor hasil tes formatif dan sumatif. Antara $40 \%-50 \%$ peserta tidak berhasil memperoleh skor passing grade pada kesempatan pertama. Mereka membutuhkan kesempatan kedua untuk mencapainya. Demikian juga pada skor tugas. Rata-rata 30\% tugas tidak sesuai dengan kriteria sehingga harus mengulang. Bahkan rata-rata $12 \%$ peserta membutuhkan perbaikan sebanyak dua kali.Fenomena tersebut menjadi indikasi kelemahan pada strategi dan media pembelajaran.

Rancangan awal sintaks belajar mengikui strategi pembelajaran online Wiliam Horton yang terdiri dari 3 langkah yaitu absorb, do dan connect (Horton, 2012: 51). Model pembelajaran tersebut diterapkan secara seragam dalam semua $\mathrm{KB}$ dengan ragam kegiatan yang relatif seragam pula yaitu membaca, diskusi dan tugas. Penerapan model ini perlu dikaji untuk perbaikan.

Berdasarkan catatan tutor penerapan model pembelajaran dengan teknik tersebut menyebabkan beberapa kelemahan sebagai berikut. a) tidak semua materi ajar dalam setiap KB cocok menggunakan model Horton. Dampaknya banyak kegiatan yang dipaksakan untuk mengikuti kerakter kegiatan absorb, do dan connect padahal substansinya tidak sesuai. B), Pola belajar seragam menyebabkan kebosanan bagi peserta.

Kelima mengenai media dan sumber belajar. Media utama penyajian menu belajar adalah Learning Management System (LMS) dengan platform MOODLE versi 2.8. Pada tahun 2012 sampai 2018 platform tersebut termasuk yang paling bayak digunakan di dunia. Selama didukung danegan bandwidth yang memadai tidak ditemukan kendala internal pada platform tersebut karena memiliki fasilitas memadai untuk menyajiakn ragam kegiatan belajar dan mengelolanya. Pada penggunaan LMS tersebut kendala ditemukan pada kapasitas SDM baik pada pengelola maupun pada peserta. Aspek yang harus dikaji adalah penggunaan format sumber belajar.

Format sumber belajar yang digunakan masih dominan teks dalam format doc, PDF dan web. Dengan format tersebut peserta hanya diberi kesempatan membaca materi ajar. Terlebih lagi 75\% kompetensi yang 
harus dikuasai berbentuk keterampilan sehinga membutuhkan contoh dan demonstrasi.

Sajian bahan ajar seperti itu tidak sesuai lagi dengan gaya belajar masyarakat di era teknologi web 2.0 yang cenderung belajar melalui kegiatan menonton.

\section{Pembahasan}

Telah dilakukan brainstorming dalam sebuah FGD melibatkan tim pengembang yang terdiri dari ahli instruksional, ahli materi dan ahli media. Dalam FGD tersebut dibahas data hasil survey, data log dan catatan lapangan kemudian dirumuskan rekomendasi untuk revisi desain instruksional.

Pertama mengenai hasil survey EELLS. Pada enam dimensi yang disurvey (Mutu Sistem/SQ, Mutu Materi Ajar/IQ, Mutu Layanan/SeQ, Dampak/U, Kepuasan Pengguna/US dan Manfaat/NB) skor rata-rata tertinggi pada dimensi manfaat dan skor ratarata terendah pada mutu materi ajar. Selanjutnya skor dapat dikelompokkan dua golongan yaitu skor di atas ratarata dan di bawah rta-rata. Skor ratarata dari semua dimensi adalah 3,90 dengan standar deviasi rataa-rata 0,19. Dengan batas rata-rata tersebut terdapat tiga dimensi yang mencapai skor di atas rata rata yaitu SQ, SE dan NB. Sisanya yaitu IQ, U dan US memperoleh skor di bawah rata-rata.

Data tersebut menggambarkan beberapa hal sebagai berikut:

a). Secara keseluruhan mutu instruksional sudah mencapai baik dengan sor rata-rata 3.90 dari skala 5 . Namun demikian tentu saja belum optimal sehingga membutuhkan upaya untuk mencapai kualifikasi sangat baik. b). Mutu sistem, mutu layanana dan manfaat sudah baik sedangkan mutu informasi, dampak dan kepuasan belum optimal masih berada pada kualifikasi cukup. Data tersebut menunjukkan bahwa sistem pembelajaran online dan layanan tutor sudah baik. Selain itu responden merasa bahwa sajian pembelajaran bermanfaat. Namun demikian secara keseluruhan responden belum merasa puas.

c). Diprediksi ketidakpuasan terkait dengan rendahnya mutu materi ajar dan dan dampak diklat terhadap diri dan pekerjaannya yang masih memperoleh kulifikasi cukup. Dimensi ini dalam kaitan desain instruksional terkait dengan aspek kompetensi yang disajikan, materi ajar dan strategi. Untuk meningkatkannya kompetensi yang disajikan harus memiliki relevansi dengan kehidupan dan pekerjaan. Selanjutnya materi diklat yag disajikan harus sinkron dengan kompetensi dan disajikan dengan strategi yang mengarah kepada peserta untuk memiliki kemampuan menerapkan hasil diklat. Sehubungan dengan itu harus dilakukan kajian dan revisi terhadap KD, materi ajar dan strategi penyajiannya.

Kedua, sebagai tindak lanjut terhadap kajian terhadap hasil survey telah dilakuakn kajian mengenai KD, materi ajar dan strategi penyajian. Berikut hasil kajian terhadap data-data yang diperoleh dari $\log$, catatan tutor dan perbincangan peserta di media social.

a). Muatan kompetensi dasar pertama dan ketiga yaitu Memahami konsep dan prosedur PTK, Memahami komponen dan sistematika PTK terlalu besar. KD pertama sebenarnya terdiri dari dua besaran yaitu paradigma penelitian dan konsep dan prosedur PTK. Berdasarkan masukan tersebut kompetensi dasar pertama dipecah menjadi dua yaitu pertama "Memahami posisi PTK dalam paradigm penelitian" dan kedua 
"Memahami komponen dan prosedur PTK".

Kompetensi Dasar mengenai paradigma penelitian perlu disajiakan secara khusus karena banyak peserta kesulitan memahami konsep PTK karena tidak memahami landasan paradigmatik. Banyak peserta yang cenderung memahami PTK sebagai penelitian positivistik sehingga rancangan PTK seperti rancangan eksperimen. Untuk mengantisipasinya harus disajikan kegiatan belajar yang menegaskan bahwa paradigma penelitian yang digunakan pada PTK adalah paradigma kritikal berbeda dengan penelitian positivistik.

Demikian juga pada KD ketiga. $\mathrm{KD}$ ini sulit disajikan dengan sederhana. Untuk menguasai KD ini dalam LMS disajikan dalam satu kegiatan belajar dengan tiga tugas yang berat, yaitu menyusun bagian pendahuluan, menyusun bagian kajian pustaka dan menyusun bagian metodologi penelitian.

Perubahan tersebut dianggap penting karena berdampak terhadap kemudahan peserta untuk memahami konsep lebih sistematik dan rinci. Berdasarkan pertimbangan tersebut diusulkan revisi kompetensi dasar sepererti pada tabel berikut.

Tabel 3 Daftar Perubahan KD

\begin{tabular}{|c|c|}
\hline $\begin{array}{c}\text { KD } \\
\text { SEBELUMNYA }\end{array}$ & KD REVISI \\
\hline \multirow{3}{*}{$\begin{array}{l}\text { Memahami } \\
\text { konsep dan } \\
\text { prosedur ptk. }\end{array}$} & \\
\hline & $\begin{array}{ll}\text { PTK } & \text { dosisi } \\
\text { paradigma penelitian }\end{array}$ \\
\hline & $\begin{array}{l}\text { Memahami konsep } \\
\text { PTK }\end{array}$ \\
\hline $\begin{array}{l}\text { Memahami } \\
\text { komponen dan }\end{array}$ & $\begin{array}{l}\text { Memahami } \\
\text { Komponen dan }\end{array}$ \\
\hline
\end{tabular}

\begin{tabular}{|c|c|}
\hline sistematika ptk & $\begin{array}{l}\text { prosedur } \\
\text { pelaksanaan PTK }\end{array}$ \\
\hline \multirow[t]{4}{*}{$\begin{array}{l}\text { Menyusun } \\
\text { proposal ptk }\end{array}$} & $\begin{array}{l}\text { Menyusun Bab } 1 \\
\text { proposal PTK }\end{array}$ \\
\hline & $\begin{array}{l}\text { Menyusun Bab } 1 \\
\text { Proposal PTK }\end{array}$ \\
\hline & $\begin{array}{l}\text { Menyusun Bab } 3 \\
\text { Proposal PTK }\end{array}$ \\
\hline & $\begin{array}{l}\text { Menyusun } \\
\text { instrument penelitian }\end{array}$ \\
\hline
\end{tabular}

b). Peserta mengelami kesulitan dalam memahami PTK karena belum mehahami posisi PTK dalam paradigma penelitian. Oleh karena itu materi tersebut harus disajikan secara khusus dan lebih mendalam. Materi tersebut harus memberikan informasi mengenai perbedaan antara paradigma penelitian dan menegaskan bahwa PTK berkembang di bawah paradigma kritikal yeng bertujuan untuk mengubah struktur sosial. Selain itu karena banyak peserta yang masih kesulitan memahami meotde pengumpulan dan analisis data maka perlu ada penegasan mengenai pendektan penelitian yang digunakan pada penelitian tindakan.

c). Kesultan peserta mengenai materi pra-PTK harus diantisipasi dengan carai menambahkan materi para-PTK lebih rinci dalam bentuk pengetahuan prosedural beserta contohnya. Materi ini harus dapat membantu peserta menyadari pentingnya pra-PTK dan memandu mereka dalam melakukan pra-PTK yang benar sehingga dihasilkan informasi awal yang cukup untuk memulai menyusun sebuah proposal penelitian.

d). Kesulitan peserta dalam menyusun instrument penelitian tindakan perlu diantisipasi dengan penambahan materi mengenai jenis-jeinis-instrumen yang digunakan dalam mix method khususnya pada instrument pengumpul data kualitatif seperti membuat rubrik analisis konten dan pertanyaan untuk 
wawancara. Materi ini perludisajikan dalam bentuk contoh dan simulasi.

e). Kelemahan peserta mengenai tata tulis ilmiah perlu mendapat perhatian karena kelemahan dalam kompetensi ini dapat membuat peserta prustrasi. Masalah teknis seperti pengutipan, penomoran bagian, penomoran halaman, membuat daftar isi dan memuat daftar pustaka merupakan momok karena dianggap sulit sehingga banyak peserta yang apatis. Hal itu diantaranya karena mereka mengalami sejenis paranoid dengan ngalaman masal lalu. Untuk mengatasinya harus disajikan materi mengenai teknis penggunaan olah kata dalam MS Word yang dapat memudhakan peserta dalam pengetikan naskah. Materi ini tidak perlu disajikan tersendiri dalam sebuah kegiatan belajar melainkan disisipkan dalam setiap bagian. Materi disajiakn dalam bentuk tutorial video dan penerapannya dalam setiap tugas membuat produk.

e). Kegitan seminar proposal online yang disajikan sebagai sebuah kegiatan khusus di akhir program terkendala teknis dan waktu. Dalam kegiatan tersebut seorang peserta mengkaji proposal tiga orang teman dan memberikan penilaian terhadap salah satunya menggunakan rubrik penilaian peoposal dan menuajikannya dalam diskusi.

Kegiatan tersebut sangat bermanfaat karena memberikan kesempatan kepada peserta untuk melihat ragam masalah dan pemikiran peserta lain yang berbeda. Namun demikian berdasarkan catatan tutor pada penyajian seminar online ditemukan kendala teknis dan waktu karena kecepatan belajar peserta tidak sama sehingga yang sudah selesai duluan harus menunggu yang belum.

Forum FGD memutuskan kegiatan belajar tersebut diganti menjadi kegiatan kompilasi. Pada sesi ini peserta menggabungkan setiap komponen proposal masing-masing, mengeditnya dan menambah dengan komponen pelengkap. Setiap peserta menyetorkan proposal lengkap sebagai tugas akhir. Apabila masih ditemukan kekurangan atau kekeliruan maka tutor memberikan umpan balik dan mengembalikannya untuk diperbaiki.

f). Perubahan substansi materi berdampak kepada struktur kuikulum. Komponen struktur kurikulum yang berubah adalah materi ajar, jumlah jam pelajaran (JP) dan jumlah minggu penyelesaian. Pada struktur kurikulm sebelumnya hanya disediakan waktu 110 JP dengan alokasi waktu yang tetap 13 minggu. Dengan penabahan substansi materi maka forum FGD mengusulkan revisi penambahan kegiatan belajar sehingga jumlah jam pelajaran menjadi menjadi 120 JP dengan waktu penyelesaian 16 minggu.

g). Sintaks kegiatan belajar yang disajikan dalam setiap KB mengikuti pola belajar online Wiliam Horton yangterdiri dari tiga kegiatan utama yaitu absorb, do dan connect. Sintaks belajar tersebut tentu tidak buruk, namun penyeragaman sintask belajar menyebabkan kebosanan. Selain itu tidak semua tujuan instruksional tepat disajikan dengan hanya satu pola pembelajaran. Oleh karena itu disarankan untuk merevisi sintask belajar pada setiap KB.

Banyak sintaks belajar yang dapat diterapkan. Bates mengidentifikasi beberapa strategi pembelajaran yang dapat digunakan sebagai sintaks pembelajaran online yaitu experiential learning, problem base learning, case base learning, inquiry base learning, dan project base learning (Bates, 2015: 91-99). Pola-pola pembelajaran tersebut dapat diterpakan pada KB-KB tertentu sesuai dengan karakter tujuan dan materi ajar sehingga pembelajaran tidak monoton. 
h). Banyak data yang menunjukkan bahwa kesulitan memahami materi ajar karena media yang digunakan semuanya masih berbentuk tesk. Media ini tidak sesuai dengan gaya masyarakat belajar di era digital. Pada zaman ini masyarakat lebih suka kepada cara-cara instan termasuk pada perilaku belajar. Budaya belajar sudah berpindah dari sekedar membaca kepada menonton. Oleh karena itu media belajarnbelajar yang digunakan tidak lagi lembaran-lembaran yang harus dibaca satu persatu melainkan dalam bentuk hypertext dan video.

Teknologi media sudah mencapai generasi Web 3.0. yang merupakan kelanjutan revolusi internet dari generasi Web 1.0 dan Web 2.0. Pada Web 3.0, pengguna bukan hanya terhubung dan berpartisipasi membuat konten informasi melainkan lebih terbuka, terhubung, dan cerdas, yang berfokus pada pemahaman data berbasis mesin. Pada Web 3.0 digunakan machine learning dan artificial intelligence (AI). Beberapa bentuk teknologi ini diantaranya adalah big data, virtual reality (VR), internet of thing (IOF) dan $3 D$ printing (Isaias et al., 2012).

Banyak penelitian mengenai penerapan Web 3.0 dalam pembelajaran seperti yang sudah dilakukan Albu mengenai alat pembelajaran Web 3.0 dalam e-learning pada jurusan teknik (Albu, 2014), penelitian Rajiv dan Lal mengenai pemanfaatan 3D-wikis, 3D Labs; Intelligent Agent based search engines, Virtual environments like Avatar and Semantic Digital Libraries (Lal \& Rajiv, 2011), dan riview literature yang dilakukan Fehmida (Hussain, 2012) menggambarkan manfaat, efisensi dan efektifitas dari penggunaan media Web 3.0 dalam pembelajaran.
Saatnya dalam DJJ digunakan teknologi tersebut. Materi ajar dan kegiatan tidak sekedar ditampilkan dalam bentuk tesk melainkan dalam bentuk hypertext berbasis semantic web yang bias menghubungkan LMS dengan berbagai sumber informasi dan kegiatan yang tersaji di wide web dengan keluasan yang nyaris tak terbatas.

Bentuk media yang sudah dapat digunakan diantaranya link LMS dengan video channel, blog, web organisasi/instansi dan media sosial. Video tutorial menjadi media penting karena masyarakat lebih suka menonton dari pada membaca teks. Sajian video tutorial memberi suasana berbeda pada pembelajaran jarak jauh. Salah satu komentar yang menarik dari peserta adalah "Lebih mudah memahmi". Selain itu media social menjadi media penting untuk komunikasi informal.

\section{KESIMPULAN}

Penelitian ini menemukan faktafakta dan dapat dirumuskan kesimulan sebagai jawaban terhadap rumusan masalah berikut

Pertama, hasil survey ISSL menunjukkan bahwa materi ajar belum sesuai dengan keinginan peserta dibuktikan dengan rendahnya pada dimensi tersebut. Hal itu ditunjukkan juga dengan rendahnya skor dimensi kepuasan dan dampak diklat.

Kedua, masih ditemukan kesulitan-kesulitan yang dialami oleh peserta dalam mempelajari materi ajar sebagai indikasi bahwa strategi pembelajaran belum baik.

Ketiga, layanan tutor sudah baik. Hal itu ditunjukkan dengan skor hasil 
survey ILLS yang mencapai angka 4.38 .

Berdasarkan kesimpulan tersebut direkomendasikan beberapa hal berikut. a). Struktur kurikulum direvisi dari hanya delapan materi menjadi sembilan materi. Penambahan materi tersebut berdampak terhadap jumlah jam pelajaran yang meningkat dari 110 JP ke 120 dan waktu penyelesaian meningkat dari 13 minggu menjadi 16 minggu. b). Penerapan strategi pembelajaran harus bervariasi pada setiap KD sesuai dengan karakter tujuan instruksinal dan materi ajar. Pola pembelajaran lain selain Horton yang tepat diterapkan adalah experiential learning, problem base learning, inquiry learning, project base laearning dan community of inquiry. c). Agar materi ajar lebih mudah dipelajari maka harus disajikan menggunakan media pembelajaran
Web 3.0. Media utama yang akan sangat bermanfaat bagi peserta adalah hypertex, video tutorial dan penggunaan media sosial. c). Selain rekomendasi sebagai implikasi dari kesimpulan, direkomendasikan juga bahwa desain instruksional harus direvisi secara berkelanjutan dilandasi dengan hasil evaluasi. Hal ini harus menjadi kebijakan pada sistem rancang bangun kurikulum kediklatan di Kementerian agama.

Penelitian ini hanya fokus pada revisi desain instruksional. Masih banyak faktor yang harus diteliti untuk meningkatkan mutu DJJ Online diantaranya aspek LMS, tutor, penyelenggara, peserta, kebijakan dan manajemen penyelenggaraan. Faktorfaktor tersebut dperu dijadikan topik penelitian berikutnya.

\section{DAFTAR PUSTAKA}

Albu, R. D. (2014). A study about Web 3.0 based e-learning tools in electrical and electronics engineering. Journal of Electrical and Electronics Engineering, 7(1), 9-12.

Arkorful, V., \& Abaidoo, N. (2015). The role of e-learning, the advantages and disadvantages of its adoption in Higher Education. International Journal of Instructional Technology and Distance Learning, 2(12), 397-410.

Bates, A. W. (Tony. (2015). Teaching in a Digital Age. In Quarterly Review of Distance Education (Vol. 16, Issue 4). Creative COmmons Attribution-NonCOmmercial 4.0.

Bawa, P. (2016). Retention in Online Courses: Exploring Issues and Solutions - A Literature Review. SAGE Open, 6(1). https://doi.org/10.1177/2158244015621777

BDK-Jakarta. (2012). Laporan Akhir Tahun Kediklatan BDK Jakarta.

Gall, M. D., Gall, J. P., \& Borg, W. R. (2015). Applying Educational Research How to Read, DO and Use Research to Solve Problems of Practice (Seventh Ed). Pearson.

Horton, W. (2012). E-Learning by Design. In Journal of Chemical Information and Modeling (2nd ed., Vol. 53, Issue 9). Pfeiffer. https:/ / doi.org/10.1017/CBO9781107415324.004 
Hussain, F. (2012). E-LEARNING 3.0=E-LEARNING 2.0+WEB 3.0? IADIS International Conference on Cognition and Exploratory Learning in Digital Age, Celda, $11-18$.

Isaias, P., Ifenthaler, D., Kinsshuk, \& Samson, D. (2012). Toward Learning and Instruction in Web 3.0 Advance in Cognitive and Educational Psychology (M. J. Spector (ed.)). Springer. https:/ / doi.org/10.1017/CBO9781107415324.004

Lal, M., \& Rajiv. (2011). Web 3 . 0 in Education \& Research. International Journal of Information Technology Bharati Vidyapeeth's Instritute of Computer Application and Management, 3(2), 335-340.

Park, J.-H., \& Choi, H. J. (2009). Factors Influencing Adult Learners' Decision to Drop Out or Persist in Online Learning. Educational Technology \& Society, 12(4), 207217. https:/ / 0 -search-proquestcom.cataleg.uoc.edu/docview /1287038599?accountid=15299

Sorensen, C., \& Donovan, J. (2017). An examination of factors that impact the retention of online students at a for-profit university. Online Learning, 21(3), 206221. https://doi.org/10.24059/olj.v21i3.935

Wang, Y. S., Wang, H. Y., \& Shee, D. Y. (2007). Measuring e-learning systems success in an organizational context: Scale development and validation. Computers in Human Behavior, 23(4), 1792-1808. https://doi.org/10.1016/j.chb.2005.10.006

Wilging, P. A., \& Johnson, S. D. (2004). Factors that influence students' decision to dropout of online courses. Journal of Asynchronous Learning, 8(4), 115-127. https://doi.org/10.24059/olj.v13i3.1659 